Article

\title{
Dietary Supplementation with Pioglitazone Hydrochloride and Resveratrol Improves Meat Quality and Antioxidant Capacity of Broiler Chickens
}

\author{
Fan Zhang ${ }^{1}$, Chenglong Jin ${ }^{1}$, Shiguang Jiang ${ }^{1}$, Xiuqi Wang ${ }^{1}$, Huichao Yan ${ }^{1}$, Huize $\operatorname{Tan}^{2}$ and \\ Chunqi Gao ${ }^{1, * \text { D }}$ \\ 1 College of Animal Science, South China Agricultural University/Guangdong Provincial Key Laboratory of \\ Animal Nutrition Control, Guangzhou 510642, China; fz@stu.scau.edu.cn (F.Z.); jin@stu.scau.edu.cn (C.J.); \\ sgjiang@stu.scau.edu.cn (S.J.); xqwang@scau.edu.cn (X.W.); yanhc@scau.edu.cn (H.Y.) \\ 2 WENS Foodstuff Group Co., Ltd., Guangzhou 527439, China; Tanhuize5@163.com \\ * Correspondence: cqgao@scau.edu.cn; Tel./Fax: +86-20-38882017
}

Received: 18 February 2020; Accepted: 30 March 2020; Published: 3 April 2020

\begin{abstract}
The study aimed to investigate the effects of pioglitazone hydrochloride (PGZ) and resveratrol (RES) on yellow-feathered broiler chickens. A total of 500 broiler chickens were randomly divided into four groups and fed a basic diet (control group) or a basic diet supplemented with $15 \mathrm{mg} / \mathrm{kg}$ PGZ, $400 \mathrm{mg} / \mathrm{kg}$ RES, or $15 \mathrm{mg} / \mathrm{kg}$ PGZ plus $400 \mathrm{mg} / \mathrm{kg}$ RES for 28 days. Compared with the control group, the PGZ and PGZ plus RES groups presented a significantly higher average daily gain and a decreased feed-to-gain ratio. Increases in the dressing percentage, semi-eviscerated yield, muscle intramuscular fat content, and $\mathrm{C} 18: 1 \mathrm{n}-9 \mathrm{c}, \mathrm{C} 18: 3 \mathrm{n}-6, \mathrm{C} 20: 3 \mathrm{n}-3$, and monounsaturated fatty acid (MUFA) percentages were found in the PGZ plus RES group. Moreover, the diet supplemented with RES or PGZ plus RES increased the activities of catalase, glutathione peroxidase, and superoxide dismutase, and decreased the levels of reactive oxygen species of thigh muscle. Additionally, the mRNA abundance of peroxisome proliferator-activated receptor $\gamma$ coactivator $1 \alpha$, fatty acid-binding protein 3 , nuclear factor erythroid-2-related factor 2, and superoxide dismutase 1 was increased in the PGZ plus RES group. In conclusion, this study suggested that dietary supplementation of PGZ combined with RES improved the growth performance, the muscle intramuscular fat content, and antioxidant ability of yellow-feathered broiler chickens.
\end{abstract}

Keywords: resveratrol; pioglitazone hydrochloride; fatty acid; meat quality; antioxidant ability; yellow-feathered broiler chicken

\section{Introduction}

In recent years, the demands of consumers have shifted from quantity to quality and, as a result, the intramuscular fat (IMF) content and fatty acid profile of poultry meat have become important to both producers and consumers [1]. Due to its relatively higher proportion of polyunsaturated fatty acids, poultry meat is usually better than other meats [2]. However, unsaturated fatty acids are susceptible to oxidation, and malonaldehyde (MDA) is well known as one of the end products of this process [3]. Thus, lipid oxidation is one of the main factors leading to the deterioration of meat quality, which can occur both before and after death [4]. Furthermore, lipid oxidation causes adverse changes in glycolysis that increase the drip loss and thereby lead to meat spoilage and a shorter shelf life $[5,6]$. Thus, an effective approach for improving the IMF and protecting intramuscular lipids against oxidative damage is needed.

Thiazolidinediones (TZDs) are a class of medicines currently been used to treat type 2 diabetes [7]. Although TZDs have beneficial effects on glycemic control, insulin sensitivity, inflammation and 
oxidative stress, and reduction of triglycerides [8-10], TZDs are clinically at risk for hepatic insufficiency, thus the use of TZDs in the animal diet is prohibited in some countries [11]. However, regarding the effects of TZDs on skeletal muscle lipid metabolism, many studies have found that intramuscular lipid content and the proportion of unsaturated fatty acids are increased after TZD treatment [12-14]. As adipogenic compounds, TZDs play a crucial role in adipocyte differentiation and have the potential to alter the formation of intramuscular or marbled fat $[15,16]$. As one of the TZDs, pioglitazone hydrochloride (PGZ) is a high-affinity ligand for peroxisome proliferator-activated receptor gamma $(P P A R \gamma)$ [17], and previous study has found that PGZ can promote adipocyte differentiation to modify intramuscular adipogenesis [15]. More adipocytes and larger cell sizes have been observed in mice supplemented with PGZ [13,14,18]. According to previous reports, PGZ has the potential to promote fat deposition in animal muscle $[19,20]$. Consistent with these findings, our previous studies confirmed that dietary supplementation with $15 \mathrm{mg} / \mathrm{kg}$ PGZ can increase the IMF in the longissimus thoracis muscle of pigs [21,22]. Therefore, PGZ has potential as a new feed additive for improving meat quality of animals. However, few studies have explored the effects of PGZ on poultry, such as chickens.

The inclusion of an antioxidant additive in broiler chicken diets is necessary to protect the PGZ supplementation-induced increase in the IMF of the thigh muscle from oxidation. Resveratrol (RES) is a botanical polyphenolic compound, and previous studies have indicated that dietary supplemental with RES could promote antioxidant activity in quail eggs and broiler chickens $[23,24]$. Furthermore, the impairment in the antioxidant status caused by heat stress is attenuated in chickens fed a diet supplemented with RES [25]. As an important plant-derived bioactive polyphenol, RES can eliminate reactive oxygen species (ROS) and thereby improve antioxidant activity [26]. Consequently, RES has the potential to work as an antioxidant and preservative to extend the shelf life of meat and thereby avoid huge economic losses.

Because RES can improve the antioxidant capacity and PGZ can enhance the IMF and proportions of unsaturated fatty acids, the aim of this study was to explore whether the combination of PGZ and RES exerts effects on the muscle antioxidant status, IMF content, and fatty acid profile of broiler chickens.

\section{Materials and Methods}

The protocols used for the feeding and management of broiler chickens in this study were approved by the Animal Ethics Committee of South China Agricultural University and were in accordance to the Guidelines for the Care and Use of Laboratory Animals of South China Agricultural University (Guangzhou, China).

\subsection{Materials}

PGZ (purity $\geq 99 \%$ ) and RES (purity $\geq 98 \%$ ) was obtained from Sichuan Jisheng Biopharmaceutical Co., Ltd. (Leshan, China).

\subsection{Experimental Design, Diets and Growth Performance}

A total of 500 female yellow-feathered broiler chickens, approximately 72 days of age (28 days before slaughter), were randomly assigned to four groups: a control group (fed with basic diet, Table S1), and the PGZ, RES, or PGZ+RES groups, which were fed the basic diet and supplemented with $15 \mathrm{mg} / \mathrm{kg}$ PGZ, $400 \mathrm{mg} / \mathrm{kg}$ RES, or $15 \mathrm{mg} / \mathrm{kg}$ PGZ + $400 \mathrm{mg} / \mathrm{kg}$ RES, respectively, for 28 days. The basic diet was formulated according to the Nutrient Requirements of Poultry (Ministry of Agriculture of the People's Republic of China 2004).

Prior to the experiment, the experimental room was cleaned and disinfected. Immunization was performed using a routine procedure. The broiler chickens were housed in a room with a concrete floor covered with wheat shavings and allowed access to feed and water ad libitum. The room was illuminated for $23 \mathrm{~h}$, and the temperature was maintained at approximately $25 \pm 2{ }^{\circ} \mathrm{C}$. Before the experiment, the animals were pre-fed with the assigned diet for 5 days, and all weak broiler chickens were eliminated. The weight and feed intake of weak broiler chickens were recorded, and these data 
were excluded in the final statistics. The experiment spanned 28 days, and the average daily feed intake (ADFI) was recorded. All broiler chickens were weighed at 1, 14, and 28 days to calculate the average daily gain $(\mathrm{ADG})$ and feed/gain $(\mathrm{F} / \mathrm{G})$ ratio.

\subsection{Serum Biochemical Indices}

After feeding for 28 days, 3 broiler chickens were selected from each replicate (totaling 15 broiler chickens per diet group) and fasted overnight for $12 \mathrm{~h}$. The broiler chickens were bled from the jugular vein, and the blood samples from the broiler chickens of the formal experiment were collected, then maintained at an oblique position for $30 \mathrm{~min}$. The serum samples were then collected after centrifugation of blood samples at $3000 \mathrm{rpm}$ for $10 \mathrm{~min}$ and stored at $-20^{\circ} \mathrm{C}$. Various serum biochemical indices, including total protein (TP), triglyceride (TG), cholesterol (CHO), low-density lipoprotein cholesterol (LDL-C), serum urea nitrogen (SUN), and high-density lipoprotein cholesterol (HDL-C), were then detected using kits (Nanjing Jiancheng Bioengineering Institute, Nanjing, China). The kits and their sensitivity and detection limits used in this study were as follows: TP assay kit A045-2-2, 5.0-122.1 U/mL; TG assay kit A110-1-1; Total CHO assay kit A111-1-1; LDL-C assay kit A113-1-1; SUN assay kit C013-2-1; and HDL-C assay kit A112-1-1.

\subsection{Carcass Performance and Meat Quality}

After blood was harvested and feathers were removed, carcass weights were calculated. The carcass traits and meat quality were measured as previously described [27]. Dressing percentage was calculated by dividing carcass weight by live weight. The semi-eviscerated yield (feet, head, and all the organs except the lungs and kidneys were removed), eviscerated yield (lung and kidney were removed), breast muscle yield ( $2 \times$ right left muscle), thigh muscle yield $(2 \times$ left thigh muscle), and abdominal fat were expressed relative to carcass weight.

The entire left breast muscle and thigh muscle (the skin was removed) were collected immediately after slaughter and used for detection of the meat quality. The $\mathrm{pH}$ was detected using a meter (HI99161, HANNA, Rome, Italy) equipped with an insertion glass electrode, and the color was detected at the same part of the front of all muscle using a colorimeter (CR410, MINOLTA, Tokyo, Japan) after 45 min and $24 \mathrm{~h}$ slaughter. The drip loss was determined with the muscle samples were suspended in a zip-lock bag and stored at $4{ }^{\circ} \mathrm{C}$ for $24 \mathrm{~h}$. The cooking loss was determined using muscle samples sealed in a zip-lock bag; the muscle samples were cooked in a $75{ }^{\circ} \mathrm{C}$ water bath and maintained at $72{ }^{\circ} \mathrm{C}$ for $20 \mathrm{~min}$. The shear force was detected using the muscle cooked in a water bath at $70^{\circ} \mathrm{C}$ for $30 \mathrm{~min}$ with a digital muscle tenderness tester (C-LM3B, TENOVO, Beijing, China) at $24 \mathrm{~h}$ after slaughter. A piece of muscle from the same location on the right side of the body was obtained and stored in liquid nitrogen for histological analysis, determination of the fatty acid composition, and RT-PCR assay. The remaining of the thigh muscle samples of each chicken were divided into 5 sections and stored at $4{ }^{\circ} \mathrm{C}$. They were then collected for the detection of the total volatile basic nitrogen (TVB-N) at $0,3,5,7$, and 9 days. As a crucial indicator used for evaluating the shelf life of meat, the TVB-N values were detected using the procedure described by Goulas [28] and expressed as mg of TVB-N/100 $\mathrm{g}$.

Six sections of thigh muscle were cut at $8 \mu \mathrm{m}$ and embedded in $4 \%$ paraformaldehyde to protect against dehydration. The sections were then stained with Oil Red $O$. The whole staining procedure lasted approximately $10 \mathrm{~min}$. Specifically, the slices were immersed in isopropanol for $2 \mathrm{~min}$, washed under running tap water for $1 \mathrm{~min}$, covered with working solution for $5 \mathrm{~min}$, and then washed in clean isopropanol for $2 \mathrm{~min}$ to adjust the slice color. A working solution composed of $0.5 \mathrm{~g}$ of Oil Red O diluted with $100 \mathrm{~mL}$ of isopropanol was prepared and stored at $4{ }^{\circ} \mathrm{C}$ [29].

\subsection{Determination of the Fatty Acid Composition}

The fatty acid contents and compositions were measured as previously described [30,31]. Samples of $30 \mathrm{~g}$ thigh muscle were baked at constant temperature (at $\left.70{ }^{\circ} \mathrm{C}\right) .2 \mathrm{~g}$ portion of each sample was weighed and then placed in a degreasing filter paper bag and dried to constant weight for 
extraction. After extraction, $2 \mathrm{~mL}$ methylation reagent (DongYing HeYi Chemical Co., LTD., Shandong, China) was taken in a $10 \mathrm{~mL}$ screw cap centrifuge tube, and accurately added to $200 \mathrm{~mL}$ of fat and gently mixed by pipetting. After sealing, the screw cap centrifuge tube was placed in a boiling water bath at $100{ }^{\circ} \mathrm{C}$ for $30 \mathrm{~min}$. The upper organic phase was transferred to a $2 \mathrm{~mL}$ centrifuge tube for centrifuge. The upper organic phase was transferred to a $1.5 \mathrm{~mL}$ gas chromatography sample vial (Jinpu Analytical Instrument Co., Ltd., Shandong, China) for later use. The fatty acid profile was detected by GC 7890A gas chromatograph (Agilent, Santa Clara, CA, USA). Nitrogen was used as carrier gas $(2 \mathrm{~mL} / \mathrm{min})$. Injector and detector temperature were $270{ }^{\circ} \mathrm{C}$. The temperature of the column was operated as follows: $75{ }^{\circ} \mathrm{C}$ for $0.5 \mathrm{~min}$, from $75{ }^{\circ} \mathrm{C}$ to $190{ }^{\circ} \mathrm{C}$ at $20^{\circ} \mathrm{C} / \mathrm{min}$, and from $190{ }^{\circ} \mathrm{C}$ to $250^{\circ} \mathrm{C}$ at $5{ }^{\circ} \mathrm{C} / \mathrm{min}$. The types of fatty acids were identified by comparing the retention times with FAME Mix 37 (18919-1 AMP, Supelco, Bellefonte, PA, USA). Contents of various fatty acids were calculated by calculating retention times and peak area percentages.

\subsection{Determination of Muscle Antioxidant Abilities and ROS}

The MDA, catalase (CAT), total superoxide dismutase (T-SOD) activity, glutathione peroxidase (GSH-Px), and total antioxidant capacity (T-AOC) of thigh muscle were determined using commercial kits (Nanjing Jiancheng Bioengineering Institute, Nanjing, China). The thigh muscles slaughtered within two hours were cut into frozen sections of $5 \mu \mathrm{m}$, washed twice with phosphate buffer saline, and returned to room temperature for incubation with $10 \mu \mathrm{M}$ dihydroethidium (DHE, 50102ES02, YEASEN, Shanghai, China) at $37^{\circ} \mathrm{C}$ for $60 \mathrm{~min}$. Fluorescence intensity was measured using Varioskan LUX (Thermo Fisher Scientific, Waltham, MA, USA).

\subsection{Determination of $m R N A$ Abundances}

Total RNA from the thigh muscle was extracted using TRIzol (Ambion, Austin, TX, USA) [32]. A quantity of 50-100 $\mathrm{mg}$ of frozen thigh muscle tissue was cut and placed in a mortar, poured into liquid nitrogen, and crushed. A quantity of $1 \mathrm{~mL}$ TRIZOL was added to separate the nucleoprotein complex. A quantity of $0.2 \mathrm{~mL}$ of chloroform was then added and the upper aqueous phase was transferred into $1.5 \mathrm{~mL}$ centrifuge tubes, to which were added $0.5 \mathrm{~mL}$ of isopropanol. A quantity of $98 \mu \mathrm{L}$ of Rnase-free water was then added after washing the RNA pellet (GeneStar, Beijing, China). The concentration of RNA was determined by NanoDrop 2000 (Waltham, MA, USA), and first-strand cDNA was synthesized with Primer Script ${ }^{\mathrm{TM}}$ (GeneStar, Beijing, China) and used for PCR amplification with T100 ${ }^{\mathrm{TM}}$ Thermal Cycler (Bio-Rad, Hercules, CA, USA). The IQ5 Real-Time PCR Detection System (Bio-Rad, CA, USA) was used to determine the mRNA abundances, and the sequences of the primers used in this study are listed in Table S2.

\subsection{Statistical Analysis}

All the data are shown as means. SPSS software (version 20.0) was used for the statistical analyses, and the statistical significance levels $(p<0.05)$ were determined by one-way analysis of variance (ANOVA) followed by Duncan's multiple range test.

\section{Results}

\subsection{Growth Performance}

The growth performances of the broiler chickens are shown in Table 1. After feeding for 28 days, the broiler chickens belonging to the PGZ and PGZ + RES groups presented heavier weights compared to the control group $(p<0.05)$. Moreover, the PGZ and PGZ + RES groups exhibited $8.92 \%$ and $9.86 \%$ lower $\mathrm{F} / \mathrm{G}$ ratios $(p<0.05)$ and $12.14 \%$ and $13.64 \%$ higher ADG values $(p<0.05)$, respectively. 
Table 1. Effects of dietary supplemental with pioglitazone hydrochloride (PGZ) and resveratrol (RES) on the growth performance of broilers.

\begin{tabular}{ccccccc}
\hline \multirow{2}{*}{ Item } & \multicolumn{9}{c}{ Treatment } & \multirow{2}{*}{ SEM } & $p$-Value \\
\cline { 2 - 5 } & Control & PGZ & RES & PGZ + RES & & \\
\hline IBW (g) & 1623.6 & 1624.2 & 1623.7 & 1624.1 & 8.24 & 0.303 \\
FBW (g) & $2112.3^{\mathrm{b}}$ & $2163.1^{\mathrm{a}}$ & $2119.6^{\mathrm{b}}$ & $2168.5^{\mathrm{a}}$ & 10.32 & $<0.05$ \\
ADFI (g) & $93.4^{\mathrm{y}}$ & $94.2^{\mathrm{a}}$ & $94.8^{\mathrm{a}}$ & $94.9^{\mathrm{n}}$ & 2.01 & 0.647 \\
ADG (g) & $17.4^{\mathrm{b}}$ & $19.2^{\mathrm{a}}$ & $17.7^{\mathrm{b}}$ & $19.4^{\mathrm{a}}$ & 0.51 & $<0.05$ \\
F/G (g/g) & $5.37^{\mathrm{a}}$ & $4.91^{\mathrm{b}}$ & $5.34^{\mathrm{a}}$ & $4.89^{\mathrm{b}}$ & 0.09 & $<0.05$ \\
\hline
\end{tabular}

a,b Values with different letters within the line mean significant differences $(p<0.05) . n=5$. Abbreviations: SEM, standard error of the means; PGZ, pioglitazone hydrochloride; RES, resveratrol; IBW, initial body weight; FBW, final body weight; F/G, feed/gain ratio; ADG, average daily gain; and ADFI, average daily feed intake.

\subsection{Serum Biochemical Indices}

As indicated by the results shown in Table 2, compared with the control group, the serum LDL-C level was significantly decreased in the broiler chickens fed with PGZ, RES, or PGZ + RES $(p<0.05)$. In addition, the broiler chickens fed with PGZ and PGZ + RES presented decreased serum CHO levels $(p<0.05)$ and increased HDL-C levels $(p<0.05)$.

Table 2. Effects of dietary supplemental with PGZ and RES on serum biochemical indices of broilers.

\begin{tabular}{ccccccc}
\hline \multirow{2}{*}{ Item } & \multicolumn{9}{c}{ Treatment } & \multirow{2}{*}{ SEM } & \multirow{2}{*}{-Value } \\
\cline { 2 - 5 } & Control & PGZ & RES & PGZ + RES & & \\
\hline SUN (mmol/L) & 0.61 & 0.50 & 0.51 & 0.59 & 0.06 & 0.331 \\
LDL-C (mmol/L) & $0.91^{\mathrm{a}}$ & $0.71^{\mathrm{b}}$ & $0.64^{\mathrm{b}}$ & $0.36^{\mathrm{c}}$ & 0.04 & $<0.05$ \\
CHO (mmol/L) & $3.30^{\mathrm{a}}$ & $2.97^{\mathrm{b}}$ & $3.20^{\mathrm{a}}$ & $2.86^{\mathrm{b}}$ & 0.11 & $<0.05$ \\
TP (g/L) & 45.53 & 46.96 & 46.70 & 48.07 & 1.45 & 0.251 \\
TG (mmol/L) & 1.73 & $1.62^{\mathrm{m}}$ & 1.78 & 1.89 & 0.57 & 0.734 \\
HDL-C (mmol/L) & $1.73^{\mathrm{b}}$ & $2.31^{\mathrm{a}}$ & $1.67^{\mathrm{b}}$ & $2.56^{\mathrm{a}}$ & 0.08 & $<0.05$ \\
\hline
\end{tabular}

${ }^{\mathrm{a}-\mathrm{c}}$ Values with different letters within the line mean significant differences $(p<0.05) . n=5$. Abbreviations: SEM, standard error of the means; PGZ, pioglitazone hydrochloride; RES, resveratrol; SUN, serum urea nitrogen; LDL-C, low-density lipoprotein cholesterol; $\mathrm{CHO}$, cholesterol; TP, total protein; TG, triglyceride; and HDL-C, high-density lipoprotein cholesterol.

\subsection{Carcass Performance and Meat Quality}

The results of carcass performance are shown in Table 3. The dressing percentages of the PGZ and PGZ + RES groups were higher than that in control group $(p<0.05)$. Moreover, the semi-eviscerated yield was significantly increased $(p=0.045$ and $p=0.037$, respectively) and the abdominal fat was decreased in PGZ, RES, and PGZ + RES supplemental groups $(p<0.05)$.

Table 3. Effects of dietary supplemental with PGZ and RES on the carcass performance of broilers.

\begin{tabular}{|c|c|c|c|c|c|c|}
\hline \multirow{2}{*}{ Item } & \multicolumn{4}{|c|}{ Treatment } & \multirow{2}{*}{ SEM } & \multirow{2}{*}{$p$-Value } \\
\hline & Control & PGZ & RES & PGZ + RES & & \\
\hline Dressing percentage (\%) & $90.96^{\mathrm{b}}$ & $91.71^{\mathrm{a}}$ & $91.54^{\mathrm{a}}$ & $91.73^{\mathrm{a}}$ & 0.20 & $<0.05$ \\
\hline Semi-eviscerated yield (\%) & $86.53^{b}$ & $87.28^{a}$ & $87.24^{\mathrm{a}}$ & $87.25^{\mathrm{a}}$ & 0.19 & $<0.05$ \\
\hline Eviscerated yield (\%) & 69.75 & 69.80 & 70.33 & 70.81 & 0.33 & 0.817 \\
\hline Breast muscle yield (\%) & 14.98 & 14.67 & 14.84 & 14.12 & 0.78 & 0.520 \\
\hline Thigh muscle yield (\%) & 17.46 & 16.71 & 16.88 & 16.2 & 0.56 & 0.793 \\
\hline Abdominal fat (\%) & $11.15^{\mathrm{a}}$ & $10.13^{b}$ & $10.12^{b}$ & $9.40^{b}$ & 0.14 & $<0.05$ \\
\hline
\end{tabular}

a,b Values with different letters within the line mean significant differences $(p<0.05) . n=5$. Abbreviations: SEM, standard error of the means; PGZ, pioglitazone hydrochloride; and RES, resveratrol. 
Relative to the control treatment, RES and PGZ + RES supplementation reduced the cooking loss and drip loss of breast muscle (Table S3) and thigh muscle (Table 4$)(p<0.05)$. In addition, the thigh muscle of broiler chickens fed RES and PGZ + RES exhibited an increased muscle $A^{*}$ (red) $(p<0.05)$ and $\mathrm{pH}(p<0.05)$ at $24 \mathrm{~h}$ after slaughter. Furthermore, the breast muscle of broiler chickens fed RES and PGZ + RES displayed a tendency toward an improved $\mathrm{pH}(p=0.08)$ at $24 \mathrm{~h}$ after slaughter. As expected, increases in the IMF values of breast muscle and thigh muscle were observed in broilers fed PGZ or PGZ + RES-supplemented diet $(p<0.01)$, as evidenced by Oil Red O staining (Figure 1).

Table 4. Effects of dietary supplemental with PGZ and RES on the meat quality in the thigh muscle of broilers.

\begin{tabular}{|c|c|c|c|c|c|c|c|}
\hline \multirow{2}{*}{ Item } & & \multicolumn{4}{|c|}{ Treatment } & \multirow{2}{*}{ SEM } & \multirow{2}{*}{$p$-Value } \\
\hline & & Control & PGZ & RES & PGZ + RES & & \\
\hline Shear force $(\mathrm{N})$ & & 23.42 & 23.44 & 23.58 & 23.23 & 0.47 & 0.935 \\
\hline Drip loss (\%) & & $1.43^{\mathrm{a}}$ & $1.41^{\mathrm{a}}$ & $1.23^{\mathrm{b}}$ & $1.20^{b}$ & 0.05 & $<0.05$ \\
\hline Cooking loss (\%) & & $22.25^{\mathrm{a}}$ & $22.85^{\mathrm{a}}$ & $19.83^{b}$ & $19.35^{b}$ & 0.76 & $<0.05$ \\
\hline $\mathrm{pH}_{45 \min }$ & & 6.02 & 5.94 & 6.06 & 5.98 & 0.06 & 0.305 \\
\hline \multirow[t]{2}{*}{$\mathrm{pH}_{24 \mathrm{~h}}$} & & $5.82^{b}$ & $5.80^{b}$ & $5.91^{\mathrm{a}}$ & $5.94^{\mathrm{a}}$ & 0.03 & $<0.05$ \\
\hline & $L^{*}$ & 52.44 & 51.93 & 51.10 & 52.21 & 0.51 & 0.532 \\
\hline \multirow[t]{3}{*}{ Color at $45 \mathrm{~min}$} & $A^{*}$ & 12.69 & 12.82 & 12.32 & 12.71 & 0.44 & 0.891 \\
\hline & $B^{*}$ & 7.39 & 7.49 & 8.17 & 8.10 & 0.67 & 0.589 \\
\hline & $L^{*}$ & 51.01 & 50.33 & 50.11 & 50.36 & 0.78 & 0.354 \\
\hline \multirow[t]{2}{*}{ Color at $24 \mathrm{~h}$} & $A^{*}$ & $11.04^{\mathrm{b}}$ & $10.87^{b}$ & $11.76^{\mathrm{a}}$ & $11.84^{\mathrm{a}}$ & 0.16 & $<0.05$ \\
\hline & $B^{*}$ & 8.23 & 8.45 & 8.56 & 10.29 & 0.43 & 0.197 \\
\hline Intramuscular fat (\%) & & $3.18^{\mathrm{b}}$ & $3.88^{\mathrm{a}}$ & $3.22^{b}$ & $4.21^{\mathrm{a}}$ & 0.15 & $<0.01$ \\
\hline
\end{tabular}

a,b Values with different letters within the line mean significant differences $(p<0.05) . n=5$. Abbreviations: SEM, standard error of the means; $L^{*}$, lightnesss; $A^{*}$, redness; $B^{*}$, yellowness; PGZ, pioglitazone hydrochloride; and RES, resveratrol.

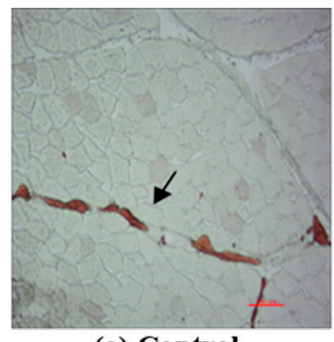

(a) Control

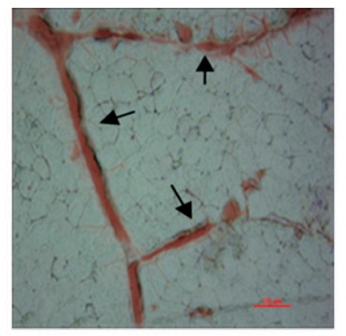

(b) PGZ

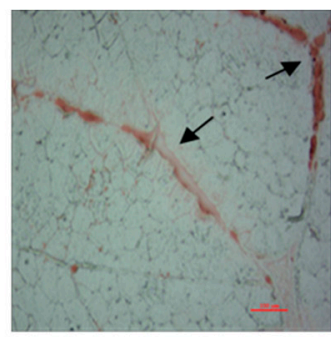

(c) RES

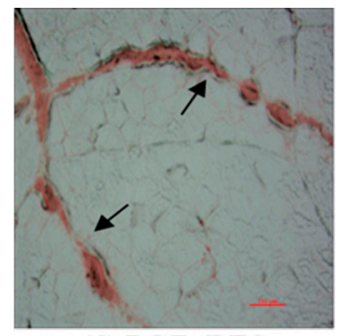

(d) PGZ+RES

Figure 1. Effects of PGZ and RES on Oil Red O staining in thigh muscle of broilers. The sections were visualized under a light microscope with $100 \times$ magnification. $n=5$. The red areas indicated by the arrows in the figure represent intramuscular fat.

\subsection{Determination of the Fatty Acid Composition}

Because of the $215.69 \%-240.35 \%$ higher IMF contents of thigh muscle compared to breast muscle (Table S3 and Table 4), we determined the fatty acid compositions of thigh muscle; results are listed in Table 5. Compared with the control group, diet supplemented with PGZ, RES, and PGZ + RES exhibited higher proportions of C18:1 $\omega-9(p=0.009, p=0.008$ and $p=0.005$, respectively) and monounsaturated fatty acid (MUFA) $(p<0.05)$. Meanwhile, the proportions of C20:3w-3 were increased in PGZ and PGZ + RES groups $(p<0.05)$. 
Table 5. Effects of diet supplemented with PGZ and RES on the fatty acid composition in the thigh muscle of broilers.

\begin{tabular}{|c|c|c|c|c|c|c|}
\hline \multirow{2}{*}{ Item } & \multicolumn{4}{|c|}{ Treatment } & \multirow{2}{*}{ SEM } & \multirow{2}{*}{$p$-Value } \\
\hline & Control & PGZ & RES & PGZ + RES & & \\
\hline C14:0 & 0.60 & 0.64 & 0.59 & 0.59 & 0.02 & 0.174 \\
\hline C16:0 & 23.16 & 23.01 & 22.76 & 23.03 & 0.42 & 0.527 \\
\hline C16:1 & 2.91 & 2.83 & 2.91 & 3.01 & 0.17 & 0.314 \\
\hline C18:0 & 8.58 & 8.39 & 8.18 & 8.16 & 0.33 & 0.937 \\
\hline C18:1w9 & $37.25^{b}$ & $38.90^{\mathrm{a}}$ & $39.03^{\mathrm{a}}$ & $39.09^{a}$ & 0.37 & $<0.05$ \\
\hline C18:2w6 & 20.99 & 20.87 & 20.39 & 21.08 & 0.25 & 0.149 \\
\hline C18:3w6 & $0.15^{b}$ & $0.18^{a}$ & $0.15^{b}$ & $0.19^{a}$ & 0.01 & $<0.05$ \\
\hline $\mathrm{C} 18: 3 \omega 3$ & 1.50 & 1.51 & 1.49 & 1.48 & 0.03 & 0.537 \\
\hline C22:0 & 0.24 & 0.21 & 0.22 & 0.21 & 0.01 & 0.217 \\
\hline $\mathrm{C} 20: 3 \omega 3$ & $0.30^{b}$ & $0.39^{a}$ & $0.32^{b}$ & $0.41^{\mathrm{a}}$ & 0.15 & $<0.05$ \\
\hline C20:4w6 & 1.73 & 1.69 & 1.74 & 1.67 & 0.15 & 0.111 \\
\hline SFA & 32.59 & 32.25 & 31.75 & 31.99 & 0.28 & 0.218 \\
\hline MUFA & $40.16^{b}$ & $41.73^{\mathrm{a}}$ & $41.94^{\mathrm{a}}$ & $42.10^{a}$ & 0.33 & $<0.01$ \\
\hline PUFA & 24.67 & 24.64 & 24.09 & 24.83 & 0.35 & 0.379 \\
\hline
\end{tabular}

${ }^{a}, \mathrm{~b}$ Values with different letters within the line mean significant differences $(p<0.05) . n=5$. Abbreviations: SEM, standard error of the means; PGZ, pioglitazone hydrochloride; RES, resveratrol; SFA, saturated fatty acid; MUFA, monounsaturated fatty acid; and PUFA, polyunsaturated fatty acid.

\subsection{Determination of Muscle Antioxidant Abilities and ROS}

The results from the analysis of the lipid antioxidant capacities are presented in Table 6. ROS levels in RES and PGZ + RES groups were significantly decreased compared with the control group $(p<0.05)$, meaning that oxidative stress in thigh muscle was attenuated by RES addition. The broiler chickens belonging to the RES and PGZ + RES groups exhibited higher thigh muscle CAT, GSH-Px, and SOD activities, and lower MDA values $(p<0.05)$ compared with the control chickens. As displayed in Figure 2, the RES group had lower TVB-N values at 5, 7, and 9 days in thigh muscle $(p<0.05)$, and the combination of PGZ with RES substantially reduced the TVB-N values of thigh muscle meat at 7 and 9 days relative to the control levels $(p<0.05)$.

Table 6. Effects of dietary supplemental with PGZ and RES on antioxidant activity in the thigh muscle of broilers.

\begin{tabular}{ccccccc}
\hline \multirow{2}{*}{ Item } & \multicolumn{7}{c}{ Treatment } & SEM & $p$-Value \\
\cline { 2 - 5 } & Control & PGZ & RES & PGZ + RES & & $<0.05$ \\
\hline ROS (\% of Control) & $1.00^{\mathrm{a}}$ & $0.83^{\mathrm{a}}$ & $0.41^{\mathrm{b}}$ & $0.35^{\mathrm{b}}$ & 0.12 & 0.978 \\
T-AOC (U/mg prot) & 0.20 & $0.21^{\mathrm{b}}$ & 0.21 & 0.25 & 0.07 & $<0.05$ \\
CAT (U/mg prot) & $2.01^{\mathrm{b}}$ & $2.05^{\mathrm{b}}$ & $2.63^{\mathrm{a}}$ & $2.65^{\mathrm{a}}$ & 0.15 & $<0.05$ \\
GSH-Px (U/mg prot) & $8.43^{\mathrm{b}}$ & $8.27^{\mathrm{b}}$ & $12.33^{\mathrm{a}}$ & $12.78^{\mathrm{a}}$ & 0.43 & $<0.05$ \\
T-SOD (U/mg prot) & $34.01^{\mathrm{b}}$ & $33.10^{\mathrm{b}}$ & $39.26^{\mathrm{a}}$ & $40.23^{\mathrm{a}}$ & 0.37 & $<0.05$ \\
MDA (nmol/mg prot) & $5.03^{\mathrm{a}}$ & $4.71^{\mathrm{a}}$ & $3.85^{\mathrm{b}}$ & $3.72^{\mathrm{b}}$ & 0.27 & $<$. \\
\hline a,b Values with different letters within the line mean significant differences ( $p<0.05) . n=5$. Abbreviations: SEM, \\
standard error of the means; PGZ, pioglitazone hydrochloride; RES, resveratrol; T-AOC, total antioxidant capacity; \\
MDA, malonaldehyde; T-SOD, total superoxide dismutase; GSH-Px, glutathione peroxidase; CAT, catalase; ROS, \\
reactive oxygen species; and prot, protein.
\end{tabular}

\subsection{Determination of $m R N A$ Abundances}

The mRNA expression levels of antioxidation- and lipogenesis-related genes in thigh muscle are shown in Figure 3. Compared with the control group, the mRNA abundances of the lipogenesis-related genes, such as PGC- $1 \alpha$ and FABP3, were greater in the PGZ and PGZ + RES groups $(p<0.05)$. Furthermore, RES and PGZ + RES supplementation resulted in an upregulation of the mRNA 
abundances of antioxidation-related genes, such as Nrf2 $(p<0.05)$ and SOD1 $(p<0.05)$. In addition, a trend toward an increased GPX 4 mRNA abundance $(p=0.07)$ was found in the PGZ + RES group.

TVB-N

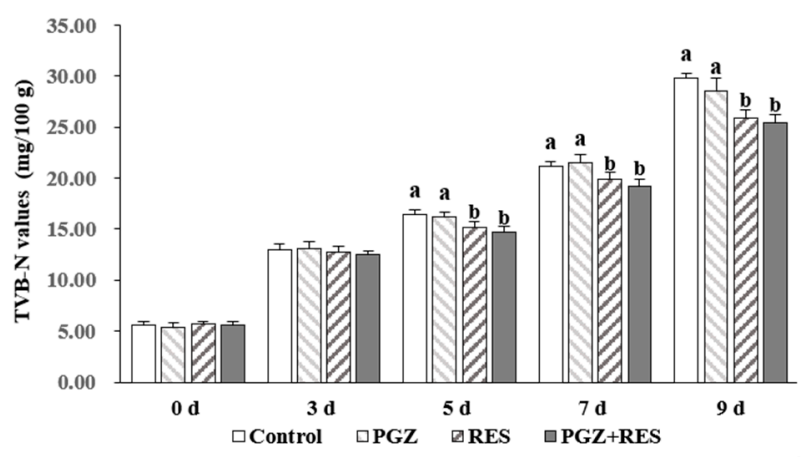

Figure 2. Effects of PGZ and RES on the TVB-N values of the thigh muscle of broilers. ${ }^{a, b}$ Values with different letters within the line mean significant differences $(p<0.05) . n=5$. Abbreviations: SEM, standard error of the means; PGZ, pioglitazone hydrochloride; RES, resveratrol; and TVB-N, total volatile basic nitrogen.
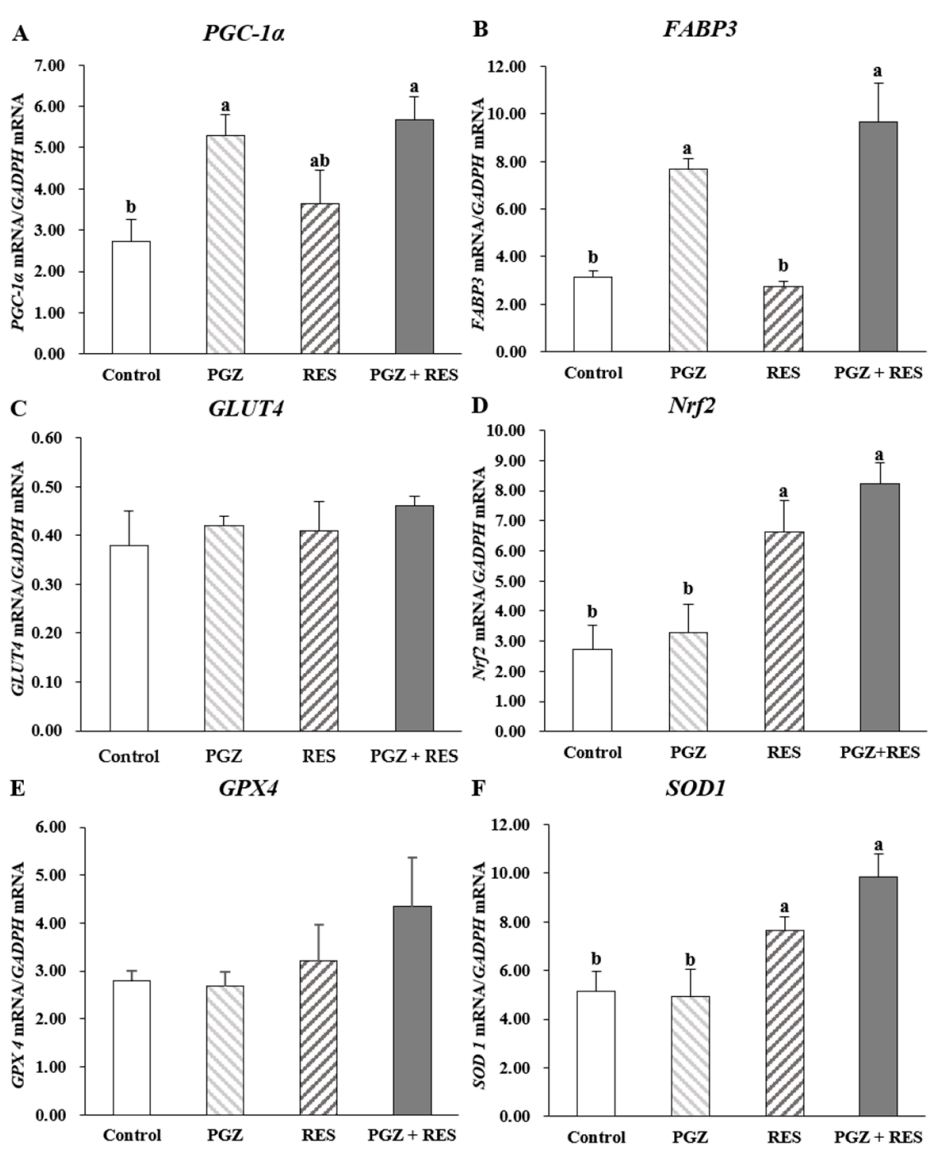

Figure 3. Effects of PGZ and RES on the mRNA abundances $\left(\times 10^{-4}\right)$ of lipogenesis-related genes, such as (A) PGC-1 $\alpha$, (B) FABP3, and (C) GLUT4, and antioxidant genes, such as (D) NRF2, (E) GPX4, and (F) $S O D 1$, in the thigh muscle of broilers. ${ }^{\mathrm{a}, \mathrm{b}}$ Values with different letters within the line mean significant differences $(p<0.05) . n=5$. Abbreviations: PGZ, pioglitazone hydrochloride; RES, resveratrol; PGC-1 $\alpha$, peroxisome proliferator-activated receptor $\gamma$ coactivator $1 \alpha$; FABP3, fatty acid-binding protein 3; GLUT4, glucose transporter 4; SOD1, superoxide dismutase 1; GPX4, glutathione peroxidase 4; and NRF2, nuclear factor erythroid-2-related factor 2. 


\section{Discussion}

The yellow-feathered broiler chicken is highly accepted in the local market of Asian countries due to its delicious meat [33]. However, the yellow-feathered broiler chicken is a slow-growing breed. The ADG and feed/gain of yellow feather broilers are approximately $18.0 \mathrm{~g} / \mathrm{d}$ and 4.8 (feed/gain, g/g), respectively [27,34]. Therefore, optimization of their feed nutrients is important for improving the growth performance of these slow-growing broiler chickens.

Our previous studies in pigs showed that dietary PGZ and PGZ + RES supplementation improved the ADG and reduced the F/G ratio, the results being consistent with this study [21,22]. The increased ADG of pig may be due to the ability of PGZ to promote adipocyte differentiation and store more fat in the body [35]. In the present study, we used low dose of PGZ as an adipogenic additive rather than as a drug, and in order to minimize the impact of PGZ on the liver and prevent drug residue in chicken products, we started to add a low dose $(15 \mathrm{mg} / \mathrm{kg})$ of PGZ to the diets one month before the chicken was released. Furthermore, broiler chickens supplemented with PGZ + RES exhibited an increased dressing percentage and a decreased abdominal fat percentage. Previous studies showed RES reduced the subcutaneous fat mass of pigs and obese rats through the inhibition of fat formation and lipolysis, which was due to the enhanced expression of silent information regulator 1 in adipocytes [36,37]. Our results show that the PGZ and PGZ + RES groups present decreased CHO and LDL-C levels but increased HDL-C concentrations, indicating that these broiler chickens exhibit an increased lipid utilization and an improved fat metabolism in vivo, which is more beneficial for IMF deposition rather than simply shifting toward abdominal fat $[22,38,39]$.

The cooking loss and drip loss are significantly decreased by PGZ + RES supplementation, which suggests an improved water holding capacity [40]. The enhanced antioxidant capacity of the PGZ + RES group is beneficial for reducing glycolysis and increasing the water storage capacity. In addition, the glycogen level largely affects the $\mathrm{pH}$ value, and we thus find that PGZ + RES supplementation increases $A^{*}$ and $\mathrm{pH}$ at $24 \mathrm{~h}$ after slaughter [21,30]. During storage, most nutrients, such as carbohydrates, proteins, and fats, decompose into various volatile organic compounds following microbial spoilage and biochemical reactions, and these basic nitrogenous compounds increase the TVB-N value, which is an important index for evaluating the shelf life of meat [41,42]. We find that the TVB-N values at 5, 7, and 9 days are decreased in the RES and PGZ + RES groups, which indicates that PGZ+RES addition has positive effects on extending the meat shelf life and improving the meat quality. PGZ targets the adipose tissue through PPAR $\gamma$ and PGC-1 $\alpha$, and the latter is used to measure the effect of PGZ [12,43]. Moreover, PGZ has potential as a new feed additive for improving meat quality because it can increase the meat IMF [30]. In this study, PGZ activates PGC-1 $\alpha$ and its downstream genes, such as $F A B P 3$, and may thus induce a more active fat metabolism. In addition, the Oil Red $\mathrm{O}$ staining results shown in Figure 1 also confirm that increased amounts of IMF are deposited in the muscles of the chickens belonging to the PGZ and PGZ + RES groups.

Higher unsaturated fatty acid proportions in meat are beneficial for human health [1]. Early studies had demonstrated that PGZ could enhance the proportions of polyunsaturated fatty acids in serum phospholipids and longissimus thoracis muscle, and MUFAs in rodent muscle [12,21,30,44]. Similar to previous studies, our present study finds that both the PGZ and PGZ+RES supplementation can increase the $\mathrm{C} 18: 1 \omega-9, \mathrm{C} 18: 3 \omega-6$, and C20:3 $\omega 3$ proportions in thigh muscle, and the latter supplementation results in higher proportions. The changes may be associated with the roles of PGZ as an affinity ligand of PPAR $\gamma$, and PGZ affects several specific genes, not only PPAR $\gamma$, but also PGC-1 $\alpha$ and FABP3, to ensure its normal function $[45,46]$. Our results support the hypothesis that PGZ improves the IMF contents and MUFA proportions by activating critical genes involved in fat metabolism. In addition, free radicals in meat can attack unsaturated fatty acids, and MDA is well known as one of the end products [3]. Our study demonstrates that dietary supplementation with RES and PGZ + RES decreases the MDA content and enhances the proportion of MUFAs in thigh muscle, which indicates that unsaturated fatty acids are protected from oxidation [47]. 
Antioxidant enzyme defensive systems, composed of SOD, GSH-Px, and CAT, can directly eliminate ROS in meat [36,44]. The content of ROS determines the degree of oxidative stress response [48]. Excessive ROS can cause cholesterol peroxidation, which in turn reduces membrane fluidity and receptor activity, thereby impairing membrane function [49]. In general, decreased lipid peroxidation or improved antioxidant ability in muscle is beneficial to meat quality. Mujahid et al. showed that excessive MDA accumulation could inhibit the activities of antioxidant enzymes and accelerate oxidative damage to proteins and DNA [50]. RES is a naturally occurring polyphenol compound, and its biological activities, including antioxidant and lipogenesis regulation, have been well researched in vitro and in vivo [51,52]. Numerous studies on the functionality of RES in poultry and pigs have confirmed its efficacy as a feed additive for improving animal production and health $[12,29]$. RES facilitates the inactivation and subsequent elimination of oxide precursors and mobilizes the expression of antioxidation-related proteins [53,54]. In our present study, the activities of the CAT, T-SOD, and GSH-Px enzymes are increased by RES and PGZ+RES supplementation, and ROS is reduced in the cells of thigh muscle. The mechanism underlying this effect may involve increased mRNA expression of NRF2, SOD1, and GPX4. NRF2 is a redox-sensitive transcription factor that can initiate the transcription of antioxidant genes, and the synthesis of CAT, SOD, and GSH-Px is regulated by NRF2 $[55,56]$. The above results of antioxidant enzyme activities are confirmed through an analysis of the antioxidant gene expression. Indeed, a strong positive correlation is found between antioxidant enzyme activities and the corresponding mRNA levels, which suggests that activities of antioxidant enzymes may be mainly regulated by their transcriptional levels [43].

From the present and some previous studies [13-22], we can conclude that dietary PGZ can increase muscle fat deposition and improve the meat quality of food animals. It has potential as a new functional feed additive. However, in many countries PGZ is a human drug and it is not allowed to be used in feeds or foods. Dietary supplementation with PGZ has the potential to generate residues in animal-derived products. There is limited information on the magnitude of PGZ residue worldwide. Therefore, extensive work has to be carried out to investigate the effects of dietary supplementation with PGZ on food-producing animals, and to prevent the occurrence of PGZ residues.

\section{Conclusions}

In conclusion, this study indicated that dietary supplementation with $15 \mathrm{mg} / \mathrm{kg}$ PGZ and $400 \mathrm{mg} / \mathrm{kg}$ RES improved the growth and carcass performances, meat quality, and antioxidant ability of yellow-feathered broiler chickens and prolonged the shelf life of the meat. Importantly, the IMF contents and MUFA proportions were improved and oxidative stress was reduced by PGZ and RES supplementation, and the mechanisms underlying these effects likely involve increases in the mRNA expression of PGC-1 $\alpha, F A B P 3, N r f 2$, and SOD1.

Supplementary Materials: The following are available online at http:/www.mdpi.com/2076-3417/10/7/2452/s1, Table S1: Composition and nutrient levels of the basic diet, Table S2: Sequences of the primers used for detection of the abundances of various genes, Table S3: Effects of dietary with PGZ and RES on the meat quality in the breast muscle of broilers.

Author Contributions: Conceptualization, H.Y. and H.T.; investigation, C.G. and X.W.; resources, C.G. and X.W.; data curation, F.Z.; formal analysis, F.Z.; writing — original draft preparation, F.Z.; writing —review and editing, C.G., C.J. and F.Z.; visualization, C.G. and S.J. All authors have read and agreed to the published version of the manuscript.

Funding: This research was supported by the Natural Science Foundation of Guangdong Province, China(2018B030315001), the Pearl River Technology Science and Technology Nova Projects of Guangzhou, China (201710010110), the Guangdong Provincial Promotion Project on Preservation and Utilization of Local Breed of Livestock and Poultry, the National Key R\&D Program of China (2018YFD0500403), and the Technical System of Poultry Industry of the Guangdong China (2019KJ128)).

Acknowledgments: Thanks for the help of the laboratory and South China Agricultural University.

Conflicts of Interest: The authors declare no conflict of interest. 


\section{References}

1. Kouba, M.; Mourot, J. A review of nutritional effects on fat composition of animal products with special emphasis on n-3 polyunsaturated fatty acids. Biochimie 2011, 93, 13-17. [CrossRef] [PubMed]

2. Bonoli, M.; Caboni, M.F.; Rodriguez-Estrada, M.T.; Lercker, G. Effect of feeding fat sources on the quality and composition of lipids of precooked ready-to-eat fried chicken patties. Food Chem. 2007, 101, 1327-1337. [CrossRef]

3. Kim, J.E.; Clark, R.M.; Park, Y.; Lee, J.; Fernandez, M.L. Lutein decreases oxidative stress and inflammation in liver and eyes of guinea pigs fed a hypercholesterolemic diet. Nutr. Res. Pract. 2012, 6, 113-119. [CrossRef] [PubMed]

4. Engel, E.J.; Ratel, J.; Bouhlel, C.; Planche, C.; Meurillon, M. Novel approaches to improving the chemical safety of the meat chain towards toxicants. Meat Sci. 2015, 109, 75-85. [CrossRef]

5. Fung, D.Y.; Toldra, F. Microbial hazards in food: Food-borne infections and intoxications. In Handbook of Meat Processing; Blackwell Publishing: Hoboken, NJ, USA, 2010; pp. 481-500. [CrossRef]

6. Dave, D.; Ghaly, A.E. Meat spoilage mechanisms and preservation techniques: A critical review. Am. J. Agric. Biol. Sci. 2011, 6, 486-510. [CrossRef]

7. Fürrnsinn, C.; Waldhausl, W. Thiazolidinediones: Metabolic actions in vitro. Diabetologia 2002, 45, 1211-1223. [CrossRef]

8. American Diabetes Association. Standards of medical care in diabetes-2014. Diabetes Care 2014, 37 (Suppl. S1), S14-S80. [CrossRef]

9. Mirmiranpour, H.; Mousavizadeh, M.; Noshad, S.; Ghavami, M.; Ebadi, M.; Ghasemiesfe, M. Comparative effects of pioglitazone and metformin on oxidative stress markers in newly diagnosed type 2 diabetes patients: A randomized clinical trial. J. Diabetes Complicat. 2013, 27, 501-507. [CrossRef]

10. Rodriguez, A.; Reviriego, J.; Karamanos, V.; del Canizo, F.J.; Vlachogiannis, N.; Drossinos, V. Management of cardiovascular risk factors with pioglitazone combination therapies in type 2 diabetes: An observational cohort study. Cardiovasc. Diabetol. 2011, 10, 18. [CrossRef]

11. Shibuya, A.; Watanabe, M.; Fujita, Y.; Saigenji, K.; Kuwao, S.; Takahashi, H. An autopsy case of troglitazone-induced fulminant hepatitis. Diabetes Care 1998, 21, 2140-2143. [CrossRef]

12. Chabowski, A.; Endzian-Piotrowska, M.; Nawrocki, A.; Górski, J. Not only accumulation, but also saturation status of intramuscular lipids is significantly affected by ppar $\gamma$ activation. Acta Physiol. 2012, 205, 145-158. [CrossRef] [PubMed]

13. Muurling, M.; Mensink, R.P.; Pijl, H.; Romijn, J.A.; Havekes, L.M.; Voshol, P.J. Rosiglitazone improves muscle insulin sensitivity, irrespective of increased triglyceride content, in ob/ob mice. Metabolism 2003, 52, 1078-1083. [CrossRef]

14. Lessard, S.J.; Lo Giudice, S.L.; Lau, W.; Reid, J.J.; Turner, N.; Febbraio, M.A.; Hawley, J.A.; Watt, M.J. Rosiglitazone enhances glucose tolerance by mechanisms other than reduction of fatty acid accumulation within skeletal muscle. Endocrinology 2004, 145, 5665-5670. [CrossRef] [PubMed]

15. Poulos, S.; Hausman, G. A comparison of thiazolidinedione-induced adipogenesis and myogenesis in stromal-vascular cells from subcutaneous adipose tissue or semitendinosus muscle of postnatal pigs. J. Anim. Sci. 2006, 84, 1076-1082. [CrossRef]

16. George, R.B.; Natasha, B.K.; Gary, F.B.; Corinne, E.C.; Yiming, L.; Laura, M.G.; Joselita, S.; Limin, P.; Francisco, P.; Denise, U. The effects of thiazolidinediones on human bone marrow stromal cell differentiation in vitro and in thiazolidinedione-treated patients with type 2 diabetes. Transl. Res. 2012, 161, 145-155. [CrossRef]

17. Machado, M.M.; Bassani, T.B.; Cóppola-Segovia, V.; Moura, E.L.; Zanata, S.M.; Andreatini, R.; Vital, M.A. PPAR- $\gamma$ agonist pioglitazone reduces microglial proliferation and $\mathrm{nf}-\mathrm{kb}$ activation in the substantia nigra in the 6-hydroxydopamine model of parkinson's disease. Pharmacol. Rep. 2019, 71, 556-564. [CrossRef]

18. MacKellar, J.; Cushman, S.W.; Periwal, V. Differential effects of thiazolidinediones on adipocyte growth and recruitment in zucker fatty rats. PLoS ONE 2009, 4, e8196. [CrossRef]

19. Arevalo-Turrubiarte, M.; Gonzalez-Davalos, L.; Yabuta, A.; Garza, J.D.; Davalos, J.L.; Mora, O.; Shimada, A. Effect of 2, 4-thiazolidinedione on limousin cattle growth and on muscle and adipose tissue metabolism. PPAR Res. 2012. [CrossRef] 
20. Schoenberg, K.M.; Overton, T.R. Effects of plane of nutrition and 2, 4-thiazolidinedione on insulin responses and adipose tissue gene expression in dairy cattle during late gestation. J. Dairy Sci. 2011, 94, 6021-6035. [CrossRef]

21. Jin, C.L.; Gao, C.Q.; Wang, Q.; Zhang, Z.M.; Xu, Y.L.; Li, H.C.; Yan, H.C.; Wang, X.Q. Effects of pioglitazone hydrochloride and vitamin $\mathrm{E}$ on meat quality, antioxidant status and fatty acid profiles in finishing pigs. Meat Sci. 2018, 145, 340-346. [CrossRef]

22. Chen, X.; Feng, Y.; Yang, W.J.; Shu, G.; Jiang, Q.Y.; Wang, X.Q. Effects of dietary thiazolidinedione supplementation on growth performance, intramuscular fat and related genes mRNA abundance in the longissimus dorsi muscle of finishing pigs. Asian Australas. J. Anim. Sci. 2013, 26, 1012-1020. [CrossRef] [PubMed]

23. Ognik, K.; Cholewińska, E.; Sembratowicz, I.; Grela, E.; Czech, A. The potential of using plant antioxidants to stimulate antioxidant mechanisms in poultry. Worlds Poult. Sci. J. 2016, 72, 291-298. [CrossRef]

24. Sahin, K.; Akdemir, F.; Orhan, C.; Tuzcu, M.; Hayirli, A.; Sahin, N. Effects of dietary resveratrol supplementation on egg production and antioxidant status. Poult. Sci. 2010, 89, 1190-1198. [CrossRef] [PubMed]

25. Liu, L.L.; He, J.H.; Xie, H.B.; Yang, Y.S.; Li, J.C.; Zou, Y. Resveratrol induces antioxidant and heat shock protein mRNA expression in response to heat stress in black-boned chickens. Poult. Sci. 2014, 93, 54-62. [CrossRef]

26. Rubiolo, J.A.; Vega, F.V. Resveratrol protects primary rat hepatocytes against necrosis induced by reactive oxygen species. Biomed. Pharmacother. 2008, 62, 606-612. [CrossRef]

27. Chen, X.; Jiang, W.; Tan, H.Z.; Xu, G.F.; Zhang, X.B.; Wei, S.; Wang, X.Q. Effects of outdoor access on growth performance, carcass composition, and meat characteristics of broiler chickens. Poult. Sci. 2013, 92, 435-443. [CrossRef]

28. Goulas, A.E.; Kontominas, M.G. Effect of salting and smoking-method on the keeping quality of chub mackerel (Scomber japonicus): Biochemical and sensory attributes. Food Chem. 2005, 93, 511-520. [CrossRef]

29. Sullivan, K.; El-Hoss, J.; Quinlan, K.G.; Deo, N.; Garton, F.; Seto, J.T. NF1 is a critical regulator of muscle development and metabolism. Hum. Mol. Genet. 2014, 23, 1250-1259. [CrossRef]

30. Jin, C.L.; Wang, Q.; Zhang, Z.M. Dietary Supplementation with Pioglitazone Hydrochloride and Chromium Methionine Improves Growth Performance, Meat Quality, and Antioxidant Ability in Finishing Pigs. J. Agric. Food Chem. 2018, 66, 4345-4351. [CrossRef]

31. Slover, H.T.; Lanza, E. Quantitative analysis of food fatty acids by capillary gas chromatography. J. Am. Oil Chem. Soc. 1979, 56, 933-943. [CrossRef]

32. Wan, X.; Ahmad, H.; Zhang, L.; Wang, Z.; Wang, T. Dietary enzymatically treated Artemisia annua L. improves meat quality, antioxidant capacity and energy status of breast muscle in heat-stressed broilers. J. Sci. Food Agric. 2018, 98, 3715-3721. [CrossRef] [PubMed]

33. Gou, Z.Y.; Jiang, S.Q.; Jiang, Z.Y.; Zheng, C.T.; Li, L.; Ruan, D.; Lin, X.J. Effects of high peanut meal with different crude protein level supplemented with amino acids on performance, carcass traits and nitrogen retention of Chinese Yellow broilers. J. Anim. Physiol. Anim. Nutr. 2016, 100, 657-664. [CrossRef] [PubMed]

34. Wang, X.Q.; Jiang, W.; Tan, H.Z.; Zhang, D.X.; Zhang, H.J.; Wei, S.; Yan, H.C. Effects of breed and dietary nutrient density on the growth performance, blood metabolite, and genes expression of target of rapamycin (TOR) signaling pathway of female broiler chickens. J. Anim. Physiol. Anim. Nutr. 2013, 97, 797-806. [CrossRef] [PubMed]

35. De Souza, C.J.; Eckhardt, M.; Gagen, K.; Dong, M.; Chen, W.; Laurent, D. Effects of pioglitazone on adipose tissue remodeling within the setting of obesity and insulin resistance. Diabetes 2001, 50, 1863-1871. [CrossRef]

36. Zhang, C.; Luo, J.; Yu, B.; Zheng, P.; Huang, Z.; Mao, X.; He, J.; Yu, J.; Chen, J.; Chen, D. Dietary resveratrol supplementation improves meat quality of finishing pigs through changing muscle fiber characteristics and antioxidative status. Meat Sci. 2015, 102, 15-21. [CrossRef] [PubMed]

37. Wang, B.; Sun, J.; Li, L.; Zheng, J.; Shi, Y.; Le, G. Regulatory effects of resveratrol on glucose metabolism and T-lymphocyte subsets in the development of high-fat diet-induced obesity in C57BL/6 mice. Food Funct. 2014, 5, 1452-1463. [CrossRef]

38. Khan, M.A.; Peter, J.V.; Xue, J.L. A prospective, randomized comparison of the metabolic effects of pioglitazone or rosiglitazone in patients with type 2 diabetes who were previously treated with troglitazone. Diabetes Care 2002, 25, 708-711. [CrossRef] 
39. Boyle, P.J.; King, A.B.; Olansky, L. Effects of pioglitazone and rosiglitazone on blood lipid levels and glycemic control in patients with type 2 diabetes mellitus: A retrospective review of randomly selected medical records. Clin. Ther. 2002, 24, 378-396. [CrossRef]

40. Mazur-Kuśnirek, M.; Antoszkiewicz, Z.; Lipiński, K.; Fijałkowska, M.; Purwin, C.; Kotlarczyk, S. The effect of polyphenols and vitamin $\mathrm{E}$ on the antioxidant status and meat quality of broiler chickens fed diets naturally contaminated with ochratoxin A. Arch. Anim. Nutr. 2019, 73, 431-444. [CrossRef]

41. Cai, J.R.; Chen, Q.S.; Wan, X.M.; Zhao, J.W. Determination of total volatile basic nitrogen (TVB-N) content and Warner-Bratzler shear force (WBSF) in pork using Fourier transform near infrared (FT-NIR) spectroscopy. Food Chem. 2011, 126, 1354-1360. [CrossRef]

42. Rukchon, C.; Nopwinyuwong, A.; Trevanich, S.; Jinkarn, T.; Suppakul, P. Development of a food spoilage indicator for monitoring freshness of skinless chicken breast. Talanta 2014, 130, 547-554. [CrossRef] [PubMed]

43. Ma, X.; Lin, Y.; Jiang, Z.; Zheng, C.; Zhou, G.; Yu, D.; Cao, T.; Wang, J.; Chen, F. Dietary arginine supplementation enhances antioxidative capacity and improves meat quality of finishing pigs. Amino Acids 2010, 38, 95-102. [CrossRef] [PubMed]

44. Veleba, J.; Kopecky, J.; Janovska, P.; Kuda, O.; Horakova, O.; Malinska, H.; Hajek, M. Combined intervention with pioglitazone and n-3 fatty acids in metformin-treated type 2 diabetic patients: Improvement of lipid metabolism. Nutr. Metab. 2015, 12, 52. [CrossRef] [PubMed]

45. Li, F.N.; Yang, H.S.; Duan, Y.H.; Yin, Y.L. Myostatin regulates preadipocyte differentiation and lipid metabolism of adipocyte via ERK1/2. Cell Biol. Int. 2011, 35, 1141-1146. [CrossRef]

46. Hondares, E.; Mora, O.; Yubero, P.; de la Concepción, M.R.; Iglesias, R.; Giralt, M.; Villarroya, F. Thiazolidinediones and rexinoids induce peroxisome proliferator-activated receptor-coactivator (PGC)- $1 \alpha$ gene transcription: An autoregulatory loop controls PGC- $1 \alpha$ expression in adipocytes via peroxisome proliferator-activated receptor- $\alpha$ coactivation. Endocrinology 2006, 147, 2829-2838. [CrossRef]

47. Zhang, C.; Luo, J.; Yu, B.; Chen, J.; Chen, D. Effects of resveratrol on lipid metabolism in muscle and adipose tissues: A reevaluation in a pig model. J. Funct. Foods 2015, 14, 590-595. [CrossRef]

48. Gill, S.S.; Tuteja, N. Reactive oxygen species and antioxidant machinery in abiotic stress tolerance in crop plants. Plant Physiol. Biochem. 2010, 48, 909-930. [CrossRef]

49. Arulselvan, P.; Subramanian, S.P. Beneficial effects of Murraya koenigii leaves on antioxidant defense system and ultrastructural changes of pancreatic b-cells in experimental diabetes in rats. Chem. Biol. Interact. 2007, 165, 155-164. [CrossRef]

50. Mujahid, A.; Akiba, Y.; Warden, C.H.; Toyomizu, M. Sequential changes in superoxide production, anion carriers and substrate oxidation in skeletal muscle mitochondria of heatstressed chickens. FEBS Lett. 2007, 581, 3461-3467. [CrossRef]

51. Paulo, L.; Ferreira, S.; Gallardo, E.; Queiroz, J.A.; Domingues, F. Antimicrobial activity and effects of resveratrol on human pathogenic bacteria. World J. Microbiol. Biotechnol. 2010, 26, 1533-1538. [CrossRef]

52. Alagawany, M.M.; Farag, M.R.; Dhama, K.; Abd El-Hack, M.E.; Tiwari, R.; Alam, G.M. Mechanisms and beneficial applications of resveratrol as feed additive in animal and poultry nutrition: A review. Int. J. Pharmacol. 2015, 11, 213-221. [CrossRef]

53. Liu, Y.; Chan, F.; Sun, H.; Yan, J.; Fan, D.; Zhao, D.; An, J.; Zhou, D. Resveratrol protects human keratinocytes HaCaT cells from uVA-induced oxidative stress damage by downregulating Keap1 expression. Eur. J. Pharmacol. 2011, 650, 130-137. [CrossRef] [PubMed]

54. Sgambato, A.; Ardito, R.; Faraglia, B.; Boninsegna, A.; Wolf, F.I.; Cittadini, A. Resveratrol, a natural phenolic compound, inhibits cell proliferation and prevents oxidative DNA damage. Mutat. Res. 2001, 496, 171-180. [CrossRef]

55. Loboda, A.; Damulewicz, M.; Pyza, E.; Jozkowicz, A.; Dulak, J. Role of Nrf2/HO-1 system in development, oxidative stress response and diseases: An evolutionarily conserved mechanism. Cell. Mol. Life Sci. 2016, 73, 3221-3247. [CrossRef] [PubMed]

56. Balasubramanian, P.; Longo, V.D. Linking Klotho, NRF2, MAP kinases and aging. Aging 2010, $2,632$. [CrossRef] [PubMed]

(C) 2020 by the authors. Licensee MDPI, Basel, Switzerland. This article is an open access article distributed under the terms and conditions of the Creative Commons Attribution (CC BY) license (http://creativecommons.org/licenses/by/4.0/). 